\title{
Pain prevalence and treatment in patients with metastatic bone disease
}

\author{
CLÁUDIA VIEIRA $^{1-3}$, MARIA FRAGOSO ${ }^{1,4}$, DEOLINDA PEREIRA ${ }^{1}$ and RUI MEDEIROS ${ }^{2,3,5,6}$ \\ ${ }^{1}$ Medical Oncology Department; ${ }^{2}$ Research Centre-Molecular Oncology Group-CI, \\ Instituto Português de Oncologia do Porto Francisco Gentil, Porto 4200-072; ${ }^{3}$ Faculty of Medicine, University of Porto; \\ ${ }^{4}$ Unit of Study and Treatment of Pain, Instituto Português de Oncologia do Porto Francisco Gentil, Porto 4200-319; \\ ${ }^{5}$ Biomedical Research Center, Faculty of Health Sciences, Fernando Pessoa University, Porto 4249-004; \\ ${ }^{6}$ Research Department, Portuguese League Against Cancer, Porto 4200-172, Portugal
}

Received April 19,2018; Accepted November 29, 2018

DOI: $10.3892 / 01.2019 .10013$

\begin{abstract}
The accomplishment of successful pain treatment requires evaluation, characterization and quantification. The present study characterized pain and survival in a cohort of patients with cancer with bone metastasis who were treated with intravenous bisphosphonates. A total of 84 patients self-completed the Brief Pain Inventory (BPI) and 36-Item Short Form Survey (SF-36), between November 2010 and March 2011 with a 5-year survival follow-up as a surrogate marker of cancer burden. The median age was 62 years old (34-85), $64 \%$ of patients were female and $58 \%$ of these females had breast cancer. In the population, self-reported pain was $91.6 \%$, with 29 patients (34.5\%) reporting severe pain (score 7-10). Among these patients, only 13 (44.8\%) presented a similar report to that of their clinical files and 5 were undergoing treatment with strong opioids (17.2\%). A total of 45 patients $(46 \%)$ had not been prescribed analgesic drugs, of these patients, 32 were treated with a weak opioid, and 13 with a strong opioid. An association was observed between pain records and the prescribed analgesic $(\mathrm{P}=0.031)$. BPI maximum pain and overall survival data were analyzed, and a significant association was identified between male patients presenting severe pain and decreased survival $(\mathrm{P}=0.004)$. Male survival was associated with severe pain, which is consistent with other data. The results revealed a skeletal-related events (SRE)-free survival (time elapsed from diagnosis of the first bone metastasis to the first SRE) of 9 months $(4.39-13.73,95 \% \mathrm{CI})$ with a statistically significant difference between subgroups of time since diagnosis of bone
\end{abstract}

Correspondence to: Dr Cláudia Vieira, Medical Oncology Department, Instituto Português de Oncologia do Porto Francisco Gentil, Rua Dr. António Bernardino de Almeida, Porto 4200-072, Portugal

E-mail: claudia.vieira@ipoporto.min-saude.pt

Key words: bone metastasis, brief pain inventory, 36-Item Short Form Survey, opioids, pain narratives, male, survival metastasis $(\mathrm{P}=0.005)$. The added value of the present study is the suggestion that complete and accurate pain narratives are mandatory and may contribute to the optimization of analgesia, and may help to increase survival rates. Optimal pain management for patients with cancer remains an urgent requirement.

\section{Introduction}

Patients with cancer may experience pain due to direct tumor effects (e.g., metastatic bone invasion) or from adverse events of treatments or pain associated with comorbidities (1-4). Bone invasion occurs in $<95 \%$ of patients with multiple myeloma, $75 \%$ of patients with breast and prostate cancer, and $15-40 \%$ of patients with other types of tumors (5-7). Bone metastases are associated with morbidities, including severe pain, pathological fractures and other oncological emergencies. These skeletal-related events (SRE) have a major impact on quality of life (8-10).

Bone metastases are caused by upregulated osteoclastic activity, leading to increased bone resorption, and are a common source of pain. Bisphosphonates (BP) are selective inhibitors of osteoclastic bone resorption (11). BPs have been used for $>15$ years, and are known to reduce and delay osteoporosis and metastatic bone disease skeletal morbidity $(12,13)$. Pamidronate (PAM) $(14,15)$ and zoledronic acid (ZOL) are widely used BPs $(8,16-22)$. More recently approved, denosumab is a human monoclonal antibody against the cytokine receptor-activated nuclear B ligand (RANKL). RANKL is involved in tumor cell migration and is a mediator of osteoclast differentiation and activation. Denosumab has also demonstrated efficacy in terms of pain palliation $(11,23)$.

Despite pain guidelines, some patients still suffer from uncontrolled pain due to drug side effects or lack of efficacy, or analgesic tolerance, all of which may lead to treatment discontinuations (24-29). Lack of knowledge of health professionals $(30,31)$, patient barriers precluding adequate treatment (e.g., fearing addiction), lack of compliance $(32,33)$ and failure to diagnose specific pain syndromes (34-36) can all lead to underuse of pain medication $(37,38)$. Different genetic predispositions for pain perception, metabolism, opioid 
receptors and transporters (39), may also result in failure of pain relief $(40,41)$.

To accomplish successful pain treatment, evaluation, characterization and quantification of pain are required. The use of the Brief Pain Inventory (BPI) $(42,43)$ is desirable in clinical practice, even outside of clinical trials (44). The scores obtained will allow more accurate comparisons between different evaluations of the same patient and patient subgroups (45). The aims of our study include the evaluation of metastatic bone pain, skeleton-related events and survival in a cohort of patients with cancer treated with intravenous BPs, crosschecks between patient pain reports [BPI and 36-Item Short Form Survey (SF-36)] and data from clinical files (pain narratives), and the influence of pain and these variables on clinical outcome and survival.

\section{Patients and methods}

Patient studies and questionnaires applied. Case selection was performed among patients undergoing BP treatment at the Day Hospital of our cancer center between November 2010 and March 2011. Recruitment included the first interview, self-filling of the BPI and SF-36 and baseline collection of data from clinical files. The patients' ability to understand the study was evaluated during the medical interview.

Although pain and quality of life were evaluated in a single interview, survival rate was determined in July 2016 (with review of medical records), to accomplish a 5-year follow-up. Breast and prostate cancer history determined a 5-year final follow-up evaluation.

Inclusion criteria were as follows: adult patients with histological confirmation of cancer with bone involvement; intravenous BP treatment (at least 1 intravenous administration); >1 month expected survival; ability to understand and answer written questionnaires; and permitting blood sample collection.

Ethical issues. Before any procedure was undertaken, all patients provided written informed consent. Ethical considerations were made as per local and national Ethics Committees and the Helsinki Declaration, and ethical approval was granted by the institutional commission of ethics.

\section{Measures}

Demographic and clinical characterization. Demographic information and clinical characteristics were collected from patient files. Performance status was assessed by Eastern Cooperative Oncology Group (ECOG) score (46). Analgesic treatment categorization was performed according to the WHO analgesic ladder: i) Non-opioid drugs (anti-inflammatory drugs or acetaminophen); second; ii) weak opioid drugs (tramadol and codeine), and iii) strong opioid drugs (fast or slow-acting morphine or equivalent patches) $(47,48)$. Invasive procedures were presented with other analgesic techniques $(49,50)$. The daily dose of morphine was based on patient reported consumption in the BPI and clinical files, using an Opioid Morphine Equivalent Conversion adapted from R. Sittle and N. Griesinger (51).

Pain and quality of life evaluation. BPI is a numerical scale with 11-points, used to measure pain intensity from $0-10$ (worst pain imaginable), and functional interference from 0-10 (complete interference) $(42,43)$. Using 'last week' as a temporal reference, the BPI questionnaire facilitates pain characterization at different levels: Maximum, minimum, average and right now $(43,44,52)$. Rating pain intensity as mild, moderate or severe was performed using the answers for 'maximum pain' according to the BPI authors' proposal; mild, score of 1-4; moderate, score of 5-6, and severe, score of 7-10 (44,52,53). Quality of life was evaluated using the 36-Item Short Form Health Survey $(42,54)$.

Statistical analysis. Data were analyzed using SPSS software (version 17.0; SPSS, Inc., Chicago, IL, USA). The $\chi^{2}$ and log-rank tests were used. Independent prognostic factors were assessed using Cox-regression, with calculation of hazard ratios and $95 \%$ confidence interval $(\mathrm{CI}) . \mathrm{P}<0.05$ was considered to be statistically significant. Survival curves were constructed using the Kaplan-Meier (KM) method and the log-rank test was used to compare differences in survival. SRE-free survival was defined as the time elapsed from diagnosis of the first bone metastases to the first SRE (SRE were considered to be events). Pathological fractures, spinal cord compression, radiotherapy of bone metastasis, neurological or orthopedic surgery and tumor-related hypercalcemia were considered to be SREs. A fracture treated with surgery and radiotherapy was considered to be a single event $(8,9)$. Overall survival (OS) was defined as the time elapsed from diagnosis to mortality or last day of follow-up (mortality due to any cause was considered an event).

\section{Results}

Authors interviewed 186 patients, but only 84 returned questionnaires with valid answers (45\% patients surveyed). Using clinical files, 79 cases (94\%) demonstrated reference to pain, 6 demonstrated pain absence, 38 demonstrated only pain location, and 10 suggested irruptive pain. Regarding intensity evaluation, moderate to severe pain (13) and mild pain (12) were reported. A total of 7 patients were lost to follow-up.

Population characterization and cancer evaluation $(n=84)$. Table I lists the social and demographic characteristics of the patients $(n=84)$. All patients were Caucasian, $64 \%$ were female and $77 \%$ were $>50$ years old (median 62 , range $34-85$ ). Sociocultural information was limited, the most common occupation was 'work at home' $(\mathrm{n}=18), 8$ patients had a university degree (9.5\%), 22 had technical training (26\%) and 2 had a military career $(2.4 \%)$. The social network was unstable in 10 cases (12\%) and based on spouse and children in 47 cases (56\%).

The most frequent types of cancer were breast, prostate and multiple myeloma. A total of 28 patients (33.3\%) exhibited bone involvement at diagnosis (including 13 myeloma cases) and 5 exhibited metastasis outside the bone (solid stage IV tumors, $n=20$ ). The median time interval from diagnosis to bone metastasis was 23 months (range, 2-91). In patients with solid tumors $(\mathrm{n}=71), 48(68 \%)$ demonstrated synchronous or metachronous disease out of the bone (non-visceral, $n=19$; visceral, $n=15$, or both, $n=14$ ).

A total of 52 patients had diagnoses of SRE. The most frequent was radiotherapy $(n=24 ; 46 \%$ of the total of SRE). 
Table I. Epidemiological, primary tumor and treatment characterization.

\begin{tabular}{|c|c|c|c|}
\hline Variable & Category & $\mathrm{N}$ & $\%$ \\
\hline \multirow[t]{2}{*}{ Sex } & Female & 54 & 64 \\
\hline & Male & 30 & 36 \\
\hline \multirow[t]{4}{*}{ Age groups (years old) } & $<50$ & 19 & 23 \\
\hline & $50-59$ & 21 & 25 \\
\hline & $60-69$ & 21 & 25 \\
\hline & $\geq 70$ & 23 & 27 \\
\hline \multirow[t]{5}{*}{ Eastern Cooperative Oncology Group score } & 0 & 14 & 17 \\
\hline & 1 & 44 & 52 \\
\hline & 2 & 14 & 17 \\
\hline & 3 & 10 & 12 \\
\hline & 4 & 2 & 2 \\
\hline \multirow[t]{4}{*}{ Primary disease } & Breast & 49 & 58 \\
\hline & Prostate & 17 & 20 \\
\hline & Multiple myeloma & 13 & 16 \\
\hline & Other & 5 & 6 \\
\hline Initial Stage at diagnosis & $\mathrm{I} / \mathrm{II}$ & 35 & 42 \\
\hline \multirow{3}{*}{ (AJCC 7th Edition TNM Staging System) } & III & 24 & 28 \\
\hline & IV & 20 & 24 \\
\hline & Unknown & 5 & 6 \\
\hline \multirow[t]{4}{*}{ Actual (baseline) anticancer treatment } & Chemotherapy & 44 & 52.5 \\
\hline & Endocrine therapy & 33 & 39 \\
\hline & Trastuzumab & 2 & 2.5 \\
\hline & Best supportive care & 5 & 6 \\
\hline \multirow[t]{4}{*}{ Therapeutic WHO analgesic ladder } & None & 8 & 9 \\
\hline & Step I & 31 & 37 \\
\hline & Step II & 32 & 38 \\
\hline & Step III & 13 & 16 \\
\hline \multirow[t]{4}{*}{ Other analgesic techniques } & Neurosurgery & 9 & 11 \\
\hline & Radiotherapy & 37 & 44 \\
\hline & Radiopharmaceuticals & 1 & 1 \\
\hline & Orthothesis & 24 & 29 \\
\hline \multirow[t]{4}{*}{ Skeletal related events } & 0 & 32 & 38 \\
\hline & 1 & 40 & 48 \\
\hline & 2 & 8 & 9 \\
\hline & 3 & 4 & 5 \\
\hline
\end{tabular}

There were 15 vertebral fractures, 1 femoral neck fracture, 12 cases of spinal cord compression syndrome and 3 cases of symptomatic hypercalcemia. The relationship between total SRE number and the impact on ECOG was significant $(\mathrm{P}<0.001)$.

Analgesic and BP treatment $(n=84)$. Analgesic treatment was recorded according to the WHO ladder (Table I). A total of 45 patients (46\%) had not been prescribed analgesic drugs, including 2 patients prescribed only adjuvant drugs. Tramadol was used to treat 22 patients, 10 patients were treated with tramadol with acetaminophen, 8 patients were treated by morphine sustained release and 5 with a transdermal patch ( 3 with fentanyl and 2 with buprenorphine). The median time interval since the beginning of opioid treatment was 9 months (range, 1-54), and the average daily dose was $98 \mathrm{mg}$ (range, 60-180). Adjuvants were used to treat 51 patients (60.7\%) and 44 patients (52.4\%) were prescribed drugs to supportive care of adverse events. Unfortunately, pain treatment was unclear in 12 cases (14.3\%). $\chi^{2}$ analysis revealed that a significant association was identified between adequate treatment and complete pain evaluation $(\mathrm{P}=0.031)$. Only 7 patients (8.3\%) had been assessed by the Pain Unit.

Intravenous PAM was the most commonly prescribed drug $(n=63)$. BP was introduced at the time of first SRE or later in 26 patients. The median time from the start of BP treatment to the first SRE was 14 months (1-83). Dental problems were reported in 24 patients and 50\% patients underwent a 
Table II. Characterization of pain and BPI pain severity rating.

\begin{tabular}{|c|c|c|c|c|c|c|c|c|}
\hline \multirow{3}{*}{$\begin{array}{l}\text { Classification of } \\
\text { the severity of pain }\end{array}$} & \multicolumn{6}{|c|}{ Characterization of pain in the last week } & \multirow{2}{*}{\multicolumn{2}{|c|}{$\begin{array}{l}\text { Pain now (at the } \\
\text { time of inventory } \\
\text { completion) }\end{array}$}} \\
\hline & \multicolumn{2}{|c|}{ Maximal pain } & \multicolumn{2}{|c|}{ Minimal pain } & \multicolumn{2}{|c|}{ Average pain } & & \\
\hline & $\mathrm{N}$ & $\%$ & $\mathrm{~N}$ & $\%$ & $\mathrm{~N}$ & $\%$ & $\mathrm{~N}$ & $\%$ \\
\hline No pain & 7 & 8.8 & 11 & 19.9 & 6 & 7.6 & 18 & 22.8 \\
\hline Mild & 22 & 27.5 & 49 & 62.0 & 34 & 43.0 & 34 & 43.0 \\
\hline Moderate & 22 & 27.5 & 12 & 15.2 & 25 & 31.6 & 15 & 17.0 \\
\hline Severe & 29 & 36.2 & 7 & 8.9 & 14 & 17.7 & 12 & 15.2 \\
\hline Total & 82 & 100 & 79 & 100 & 79 & 100 & 79 & 100 \\
\hline
\end{tabular}

The classification of the severity of pain as mild, moderate or severe was made according to the proposal of the authors of the original BPI, e.g., using the answers to the question about pain in the 'maximum' and stratifying on 1-4 (mild pain), 5-6 (moderate) and 7-10 (severe). BPI, Brief Pain Inventory.

Table III. BPI pain severity rating and its relation with analgesic therapy.

\begin{tabular}{|c|c|c|c|c|c|}
\hline \multirow[b]{2}{*}{ Intensity } & \multicolumn{5}{|c|}{$\begin{array}{c}\text { Pain intensity vs. analgesic therapy } \\
\text { Analgesic }\end{array}$} \\
\hline & None & Non-opioid & Weak opioid & Strong opioid & Total \\
\hline No pain & 1 & 3 & 3 & 0 & 7 \\
\hline Mild & 3 & 7 & 10 & 2 & 22 \\
\hline Moderate & 1 & 10 & 6 & 3 & 20 \\
\hline Severe & 2 & 9 & 13 & 5 & 29 \\
\hline Total & 7 & 29 & 32 & 10 & 78 \\
\hline
\end{tabular}

The classification of the severity of pain as mild, moderate or severe was made according to the proposal of the authors of the original BPI, e.g., using the answers to the question about pain in the 'maximum' and stratifying on 1-4 mild pain, moderate 5-6 and 7-10 severe. Brief Pain Inventory.

dental consultation prior to BP treatment. BP interruptions $(n=25,30 \%)$ were due to dental treatment $(n=16)$, jaw osteonecrosis $(n=3)$, impaired kidney function $(n=4)$ or bone marrow transplantation $(\mathrm{n}=2)$.

Pain and quality of life evaluation $(n=80)$. BPI overall incidence of pain was $91.6 \%$ (considering answers to 'maximum pain' during the last week, $\mathrm{n}=80$ ), including $27.5 \%$ reporting mild pain, $27.5 \%$ reporting moderate pain and $36.2 \%$ reporting intense pain (Tables II-IV). For the 'minimum pain' question, $24 \%$ patients reported moderate and $32 \%$ reported severe pain. For the 'pain right now' question, a statistically significant difference was demonstrated between the answers to the different questions $(\mathrm{P}<0.001)$. A total of 32 patients $(38 \%)$ performed BPI evaluation before the first SRE.

Only 1 patient reported complete relief with therapy and $54 \%$ reported pain reduction $>50 \%$. A total of 32 patients reported insufficient relief $(0-40 \%), 22$ reported moderate relief (50-60\%) and 20 reported significant relief (70-100\%). A total of 27 patients, $53 \%$ of those reporting moderate to severe pain, underwent opioid treatment, with $16 \%$ treated with a strong opioid (Tables III and IV).
Cancer pain severity affects general activity $(\mathrm{P}<0.001)$, mood $(\mathrm{P}=0.001)$, ability to walk $(\mathrm{P}=0.001)$, ability to perform normal work $(\mathrm{P}<0.001)$ and the joy of living $(\mathrm{P}=0.033)$. As pain intensity increases, interference with daily activities also increases (score $\geq 5$ ). No statistically association was identified in terms od sleep, social relationships and reported pain vs. therapeutic regimen (Tables III and IV). Table V presents relevant data from the SF-36 Quality of Life Questionnaire is presented. The adherence to self-fulfilling was lower than that of the BPI assessment.

Breast cancer subgroup. A total of 49 patients (58\%) had a primary tumor of the breast, the median age of whom was 58 years (range, $34-85$ ) and only 2 patients had triple negative tumors (Table VI). Twelve patients presented with bone metastases at diagnosis (24.5\%). At the time of BPI completion, 29 patients $(59.2 \%)$ presented with disseminated predominantly blastic bone disease. 1 SRE was recorded for 27 patients (55.1\%) and $\geq 1$ in 4 patients $(8.2 \%)$. The mean value of CA 15.3 was $244 \mathrm{U} / \mathrm{ml}$ (range, 12-2246), with 9 patients presenting normal values $(<30 \mathrm{U} / \mathrm{ml})$. The median time interval since diagnosis was 70 months (range, 6-278) and the median time 

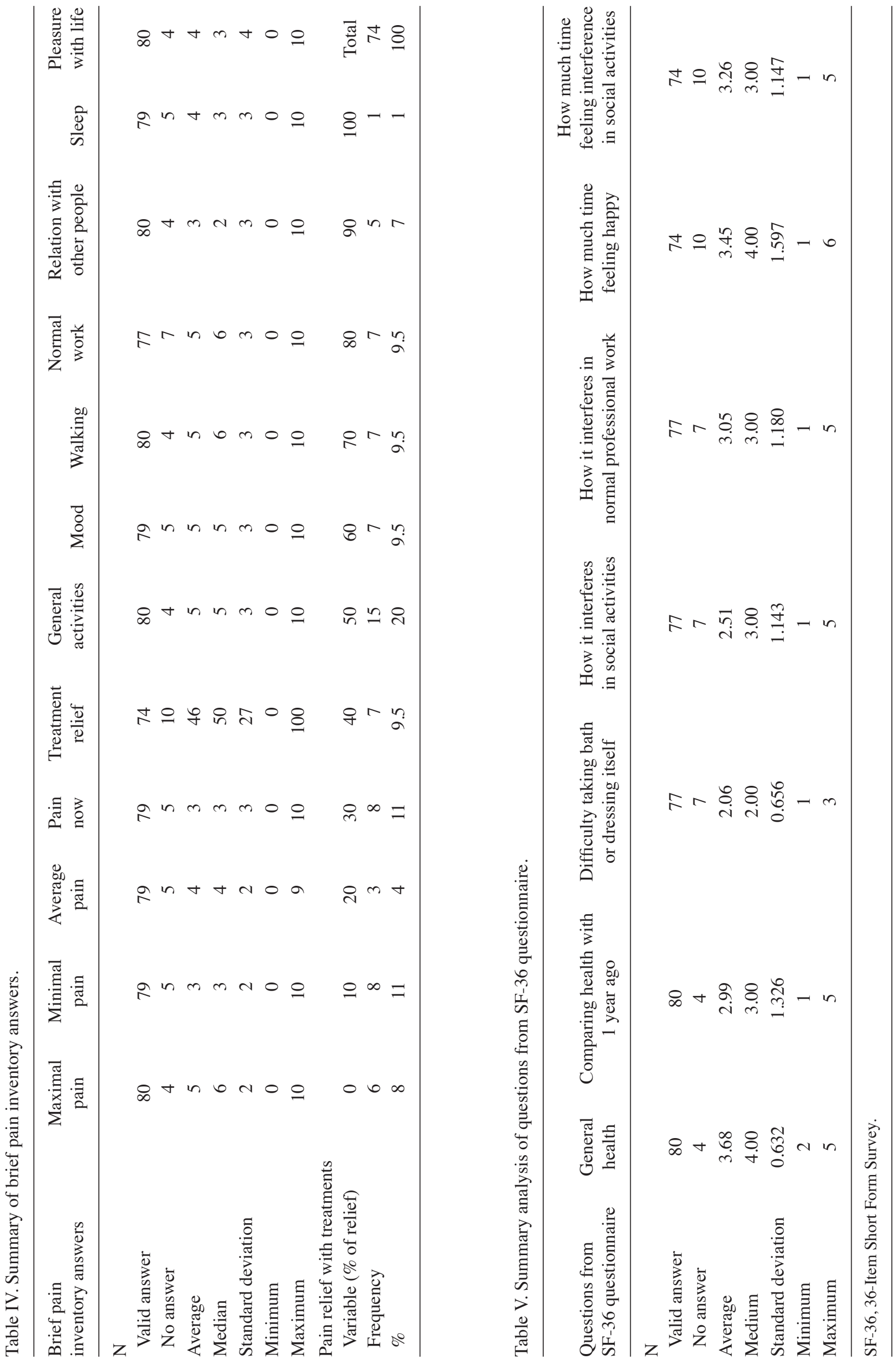
interval since bone metastasis was 27 months (range, 4-91). In BPI, 31 patients reported moderate or severe pain $(63.26 \%)$ and in the Quality of Life Questionnaire, 22 patients reported feeling happy for a 'small part of the time' or 'never' (>50\%). Only 6 patients underwent treatment with strong opioid (12\%). There were no statistically significant differences in terms of pain severity among the different characteristics of this subgroup.

Survival data $(n=84)$. To better understand cancer burden and treatment outcomes, a 5-year period was considered for survival time. In 2011, when the 84 questionnaires were completed, only 4 patients suffered mortality. OS analysis revealed a statistically significant association between tumors $(\mathrm{P}=0.035)$ and stage at diagnosis $(\mathrm{P}<0.001)$ with OS. ECOG was also significantly associated with $\mathrm{OS}(\mathrm{P}=0.002)$. Data regarding 'maximum pain' during the last week was analyzed in terms of OS, and a statistically significant association was identified in the male subgroup, with decreased survival associated with patients with intense pain $(\mathrm{P}=0.004)$. Average SRE-free survival was 9 months (range, 4.39-13.73, 95\% CI). Statistically significant differences between subgroups were identified for time since diagnosis of bone metastasis $(\mathrm{P}=0.005)$ in terms of SRE-free survival. A statistically significant association was found between stage at diagnosis and SRE-free survival $(\mathrm{P}<0.001)$, with decreased survival demonstrated for patients with stage IV disease. Neither OS nor SRE-free survival were associated with age, female sex, baseline anticancer treatment, SRE number, presence of visceral metastasis or other BPI answers (namely, number of pain locations).

\section{Discussion}

Adequate treatment of pain may be limited by the patient, health professional or national health system (25,30-33). To evaluate pain intensity, scales such as visual analog, numerical rating, faces or qualitative scales are the most frequently used procedures $(3,30,53,55,56)$. Only $25 / 79$ patients $(31 \%)$ presented evaluation of pain intensity using these methodologies in the present study. Inventories aim to assess pain in a more comprehensive way, but they are time and resource consuming $(3,43,44,52)$.

In the present study, breast and prostate cancer were the most prevalent, and multiple myeloma the least prevalent. This is consistent with the reported prevalence of the population (57-60). Furthermore, at diagnosis, 28\% patients with solid tumors present with stage IV disease. Considering BPI results, overall pain incidence was $91.6 \%$, higher than that previously reported for cancer patients (55). A total of 32 patients performed BPI prior to the first SRE. In March 2007, a systematic review was published, reporting an overall prevalence of cancer pain of 59\% (95\% CI, 44-73), using visual or numerical scaling, verbal characterization or simply 'yes or no' methods (56). In September of the same year (2007) a systematic review of 40 years of literature concluded that $64 \%$ of patients with advanced or metastatic cancer reported pain; $59 \%$ of patients receiving anticancer treatment reported pain, and a third of patients reported pain after completing curative treatment. These data suggest that the prognosis of the primary tumor and cancer burden may not be proportional to pain (56).
Table VI. Breast cancer subgroup characterization.

\begin{tabular}{|c|c|c|c|}
\hline Breast cancer & Variable & $\mathrm{N}$ & $\%$ \\
\hline \multirow[t]{4}{*}{ Histological subtype } & Ductal & 34 & 67.3 \\
\hline & Lobular & 4 & 8.2 \\
\hline & Mixed & 6 & 12.2 \\
\hline & Unknown & 5 & 10.2 \\
\hline \multirow[t]{4}{*}{ Grade } & $\mathrm{I}$ & 2 & 4.1 \\
\hline & II & 33 & 67.3 \\
\hline & II & 7 & 14.3 \\
\hline & Unknown & 7 & 14.3 \\
\hline \multirow[t]{3}{*}{ Endocrine receptors } & Positives & 42 & 85.7 \\
\hline & Negatives & 5 & 10.2 \\
\hline & Unknown & 2 & 4.0 \\
\hline \multirow[t]{3}{*}{ HER2 } & Positive & 5 & 10.2 \\
\hline & Negative & 34 & 69.4 \\
\hline & Unknown & 10 & 20.4 \\
\hline Initial Stage at diagnosis & I & 5 & 10.2 \\
\hline (AJCC 7th Edition TNM & II & 21 & 42.9 \\
\hline \multirow[t]{2}{*}{ Staging System) } & III & 11 & 22.4 \\
\hline & IV & 12 & 24.5 \\
\hline \multirow{4}{*}{$\begin{array}{l}\text { Current anticancer } \\
\text { treatment }\end{array}$} & ChT & 23 & 46.9 \\
\hline & ET & 22 & 44.9 \\
\hline & Trastuzumab & 2 & 4.1 \\
\hline & ChT+trastuzumab & 2 & 4.1 \\
\hline \multirow[t]{4}{*}{ Others metastasis } & None & 15 & 30.6 \\
\hline & Non-visceral & 6 & 12.2 \\
\hline & Visceral & 17 & 34.7 \\
\hline & Both & 11 & 22.4 \\
\hline
\end{tabular}

HER2, human epidermal growth factor receptor 2; ChT, chemotherapy; ET, endocrine therapy.

Although initial surveying took place in 2011, a 5-year follow up of survival was performed to determine disease aggressiveness as well as treatment outcomes (in addition to baseline data regarding disease, metastatic pattern and anticancer treatment).

Pain perception by patients may not be coincident with health professional evaluation. For example, we observed that $63.7 \%$ of patients reported moderate to severe pain by BPI, but this was only reflected in the clinical files of $15.4 \%$ patients. Only 5 patients were treated with strong opioids (17\%) and 7 patients were assessed in the Pain Unit (8.3\%). These data suggest that overconsumption of anti-inflammatory drugs to the detriment of opioids may explain why $73 \%$ of patients reported inadequate relief via BPI.

Our results suggest that $\mathrm{BP}$ and adequate analgesia were prescribed late in the course of disease (prescribed after first SRE in $31 \%$ patients). SRE number was statistically associated with the interval between of BP therapy and ECOG. The opioid of use, SRE and ECOG were demonstrated to impact patient capacity for self-care, general activity, ability to walk and performance of normal work. 
In some countries, opioids are unavailable, and in others their abusive use has resulted in a period of opioid avoidance (41). We believe that the high prevalence of pain in the present population is associated with subdiagnosis, insufficient characterization and consequent misapplication of the analgesic pain scale. Cancer pain represents a particular entity and can be treated with the same approach as that for degenerative osteo-articular pathology, for example $(25,32,48,61)$. The systematic and complete characterization of pain, using tools that allow for the assessment of severity with accuracy and reproducibility, poses an ethical issue. Cancer pain severity affects mood and quality of life, and has been suggested to be related to pain relief treatment.

Decreased survival times of male patients reporting intense pain were independent of primary disease or SRE number (considering answers to "maximum pain during the last week). This may be due to a number of reasons, including psychological, sociological and genetic differences. Males may experience a different perception of pain, or interact differently with healthcare professionals than females. Furthermore, we they may suggest that males present a better accuracy in pain characterization. In a recent report of health-related quality of life (EQ-5D-5L), it was concluded that men score increased mean values using the visual analog scale (VAS) than women, and that, overall, the VAS mean decreases with age (62). Santoro et al (63) found significant sex differences in regional brain glucose metabolism associated with opioid withdrawal. However, this study was performed in a different setting of patients and with a different treatment goal. It has been suggested that the clinical response to buprenorphine or methadone can depend on sex; with females having more success using pharmacological treatments for opioid dependence compared with males. Clinical treatment failure has been more commonly reported in males (63). Sex differences in terms of pain were also identified in patients with fibromyalgia and burning mouth syndrome $(64,65)$. Future clinical trials should specifically address the variables associated with sex in cancer patients. The small number of male patients in the present study $(n=30)$ is a limitation, and further investigation using a larger sample size is required.

The relationship between the total SRE number and the impact on ECOG was statistically significant. SRE number had a functional impact on the daily activities of the patients. Bone metastasis at diagnosis and ECOG impacted OS, independent of pain scores. Cancer pain severity affects general activity, ability to walk, performance of normal work, mood and quality of life. Breast and prostate cancer treatments have improved over the last decade; however, performance status and the biology of bone metastasis remain the determinant factors of survival. A recent study of non-small cell lung cancer (NSCLC) reported that patients with stage I-III disease treated with BPs had improved outcomes compared with those without treatment. However, no difference was observed for patients with stage IV disease. The authors concluded that the factors associated with OS and SRE-free survival of patients with NSCLC and bone metastases remain unknown (66).

The associations between BPI evaluation and clinical impacts are consistent with previous studies $(44,67)$. Pain remains a serious public health problem. Despite published legislation and training of health professionals, pain characterization by medical interview and pain narratives are not exhaustive enough to facilitate correct or sufficient pain management, or to improve palliative care and costs to national health systems (particularly in Portugal) (23).

The overuse of unidimensional scales may compromise the evaluation process, to the extent that malignant bone pain becomes a subjective complaint, leading to difficulties in the establishment of quantitative values and corresponding normal cutoffs.

The use of BPI and other tools, such as quality of life questionnaires, can be effective for patients with cancer pain, and they are desirable in clinical practice. Male survival was associated with severe pain, which is consistent with recent data, which suggested that treatment failure is more commonly experienced by male. The potential significance of sex should be addressed in future study.

There are a number of limitations of the present study. The sample of cancer patients from a single cancer center was small, with only one single point assessment of BPI and SF-36. However, to the best of our knowledge, this is the first study to represent the Portuguese population with cancer. Although we considered primary disease, initial staging, baseline anticancer treatment, SRE number, the presence of visceral metastasis (in addition to bone disease) and 5-year survival, our results may be biased by variety in types of cancer and/or tumor burden. The prevalence of breast and prostate cancer was high in the present study. Therefore, the impact of pain on survival may be less influenced by cancer prognosis (68). A recent systematic review addressing the impact of pain on the survival of cancer patients revealed that pain can be an independent prognostic factor in advanced prostate cancer. The authors also highlighted the interference of opioid treatment, which was less prevalent in the present study (69). It is unclear from the existing literature whether severity of pain is associated with survival. The results of the present study may guide the design of further studies with more homogeneous populations and better estimations of tumor burden, to ultimately improve pain characterization and effective pain relief.

The present study reinforces the requirement for complete and accrued pain narratives, using BPI and quality of life questionnaires, in patients with cancer. Furthermore, it was suggested that these tools may contribute to the optimization of analgesia and may increase life expectancy. Further clinical studies and pain assessment data banks (with multiple evaluations of BPI and quality-of-life questionnaires or others tools) should be implemented to validate the importance of these tools.

\section{Acknowledgements}

The authors would like to thank Dr Ana Correia de Oliveira and all of the team of the Research Center-Molecular Oncology Group; Medical Oncology and Hematology Department, Unit of Study and Treatment of Pain, Teamwork of Daily Hospital and Blood Collection Station/Clinical Laboratory of Francisco Gentil Portuguese Institute of Oncology, Porto, Portugal for helping to identify potential patients.

\section{Funding}

The present study was developed as part of a project selected as an internal clinical research project of Francisco Gentil 
Portuguese Institute of Oncology, Porto, Portugal (Bulletin 8/2017, CI-IPOP 70/2017).

\section{Availability of data and materials}

The datasets used and/or analyzed during the current study are available from the corresponding author on reasonable request.

\section{Authors' contributions}

CV collected all the data and performed the statistical analyses. MF, DP and RM interpreted the results, assisted with statistical analyses and manuscript writing. The final manuscript has been reviewed and approved by all authors.

\section{Ethics approval and consent to participate}

Ethical considerations respected local and national Ethics Committee and Helsinki Declaration. The study protocol was approved by Instituto Português de Oncologia do Porto Francisco Gentil (IPO-PORTO) ethical committee. All patients provided written informed consent.

\section{Patient consent for publication}

Not applicable.

\section{Competing interests}

The authors declare that they have no competing interests.

\section{References}

1. Marcus NJ: Pain in cancer patients unrelated to the cancer or treatment. Cancer Invest 23: 84-93, 2005.

2. Williams AC and Craig KD: Updating the definition of pain. Pain 157: 2420-2423, 2016.

3. Alcock MM: Defining pain: Past, present, and future. Pain 158: 761-762, 2017.

4. Izumi H, Igishi T, Yamasaki A, Takeda K, Yanai M, Tanaka N, Sakamoto T, Nishii-Ito S, Touge H, Kodani M, et al: Development of fever following first administration of zoledronate as a prognostic factor in advanced non-small cell lung cancer patients with bone metastases. Mol Clin Oncol 7: 1000-1004, 2017.

5. Roodman GD: Mechanisms of bone metastasis. N Engl J Med 350: 1655-1664, 2004

6. Coleman RE: Metastatic bone disease: Clinical features, pathophysiology and treatment strategies. Cancer Treat Rev 27: 165-176, 2001.

7. Luo Q, Xu Z, Wang L, Ruan M and Jin G: Progress in the research on the mechanism of bone metastasis in lung cancer. Mol Clin Oncol 5: 227-235, 2016.

8. Bell R: Efficacy of ibandronate in metastatic bone disease: Review of clinical data. The oncologist 10 (Suppl 1): S8-S13, 2005.

9. Fontanella C, Fanotto V, Rihawi K, Aprile G and Puglisi F: Skeletal metastases from breast cancer: Pathogenesis of bone tropism and treatment strategy. Clin Exp Metastasis 32: 819-833, 2015.

10. Kolesnikov-Gauthier H, Lemoine N, Tresch-Bruneel E, Olivier A, Oudoux A and Penel N: Efficacy and safety of ${ }^{153} \mathrm{Sm}$-EDTMP as treatment of painful bone metastasis: A large single-center study. Support Care Cancer 26: 751-758, 2018.

11. Vardy J and Agar M: Nonopioid drugs in the treatment of cancer pain. J Clin Oncol 32: 1677-1690, 2014.

12. Aapro M, Abrahamsson PA, Body JJ, Coleman RE, Colomer R, Costa L, Crinò L, Dirix L, Gnant M, Gralow J, et al: Guidance on the use of bisphosphonates in solid tumours: Recommendations of an international expert panel. Ann Oncol 19: 420-432, 2008.
13. Idota A, Sawaki M, Yoshimura A, Hattori M, Inaba Y, Oze I, Kikumori T, Kodera Y and Iwata H: Bone Scan Index predicts skeletal-related events in patients with metastatic breast cancer. Springerplus 5: 1095, 2016.

14. Pavlakis N, Schmidt R and Stockler M: Bisphosphonates for breast cancer. Cochrane Database Syst Rev: CD003474, 2005.

15. Small EJ, Smith MR, Seaman JJ, Petrone S and Kowalski MO: Combined analysis of two multicenter, randomized, placebo-controlled studies of pamidronate disodium for the palliation of bone pain in men with metastatic prostate cancer. J Clin Oncol 21: 4277-4284, 2003.

16. Coleman RE: Bisphosphonates: Clinical experience. Oncologist 9 (Suppl 4): S14-S27, 2004.

17. Rosen LS, Gordon D, Kaminski M, Howell A, Belch A, Mackey J, Apffelstaedt J, Hussein MA, Coleman RE, Reitsma DJ, et al: Long-term efficacy and safety of zoledronic acid compared with pamidronate disodium in the treatment of skeletal complications in patients with advanced multiple myeloma or breast carcinoma: A randomized, double-blind, multicenter, comparative trial. Cancer 98: 1735-1744, 2003.

18. Wardley A, Davidson N, Barrett-Lee P, Hong A, Mansi J, Dodwell D, Murphy R, Mason T and Cameron D: Zoledronic acid significantly improves pain scores and quality of life in breast cancer patients with bone metastases: A randomised, crossover study of community vs hospital bisphosphonate administration. Br J Cancer 92: 1869-1876, 2005.

19. Shapiro CL, Moriarty JP, Dusetzina S, Himelstein AL, Foster JC, Grubbs SS, Novotny PJ and Borah BJ: Cost-effectiveness analysis of monthly zoledronic acid, zoledronic acid every 3 months, and monthly denosumab in women with breast cancer and skeletal metastases: CALGB 70604 (Alliance). J Clin Oncol 35: 3949-3955, 2017.

20. Shapiro CL and Himelstein AL: Zoledronic acid dosing in patients with metastatic breast cancer. JAMA Oncol 4: 585-586, 2018.

21. Himelstein AL, Loprinzi CL and Shapiro CL: Zoledronic acid dosing interval for metastatic cancer-reply. JAMA 317: 1478, 2017.

22. Himelstein AL, Foster JC, Khatcheressian JL, Roberts JD, Seisler DK, Novotny PJ, Qin R, Go RS, Grubbs SS, O'Connor T, et al: Effect of longer-interval vs standard dosing of zoledronic acid on skeletal events in patients with bone metastases: A randomized clinical trial. JAMA 317: 48-58, 2017.

23. von Moos R, Costa L, Ripamonti CI, Niepel D and Santini D: Improving quality of life in patients with advanced cancer:Targeting metastatic bone pain. Eur J Cancer 71: 80-94, 2017.

24. Burton AW and Cleeland CS: Cancer pain: Progress since the WHO guidelines. Pain Pract 1: 236-242, 2001.

25. Varrassi G, Müller-Schwefe G, Pergolizzi J, Orónska A, Morlion B, Mavrocordatos P, Margarit C, Mangas C, Jaksch W, Huygen F, et al: Pharmacological treatment of chronic pain-the need for CHANGE. Curr Med Res Opin 26: 1231-1245, 2010.

26. Lara-Solares A, Ahumada Olea M, Basantes Pinos ALÁ, Bistre Cohén S, Bonilla Sierra P, Duarte Juárez ER, Símon Escudero OA, Santacruz Escudero JG and Flores Cantisani JA: Latin-American guidelines for cancer pain management. Pain Manag 7: 287-298, 2017.

27. Yoshimoto T, Tomiyasu S, Saeki T, Tamaki T, Hashizume T, Murakami M and Matoba M; Symptom Control Research Group (SCORE-G): How do hospital palliative care teams use the WHO guidelines to manage unrelieved cancer pain? A 1-year, multicenter audit in Japan. Am J Hosp Palliat Care 34: 92-99, 2017.

28. Martínez-Nicolás I, Ángel-García D, Saturno PJ and López-Soriano F: Cancer pain management: Systematic review and critical appraisal of clinical practice guidelines. Rev Calid Asist 31: 55-63, 2016 (In Spanish).

29. Carlson CL: Effectiveness of the World Health Organization cancer pain relief guidelines: An integrative review. J Pain Res 9: 515-534, 2016.

30. Sloan PA, Donnelly MB, Schwartz RW and Sloan DA: Cancer pain assessment and management by housestaff. Pain 67: 475-481, 1996.

31. Warncke T, Breivik H and Vainio A: Treatment of cancer pain in Norway. A questionnaire study. Pain 57: 109-116, 1994.

32. Paice JA, Toy C and Shott S: Barriers to cancer pain relief: Fear of tolerance and addiction. J Pain Symptom Manage 16: 1-9, 1998.

33. Miaskowski C, Dodd MJ, West C, Paul SM, Tripathy D, Koo P and Schumacher K: Lack of adherence with the analgesic regimen: A significant barrier to effective cancer pain management. J Clin Oncol 19: 4275-4279, 2001. 
34. Caraceni A, Martini C, Zecca E, Portenoy RK, Ashby MA, Hawson G, Jackson KA, Lickiss N, Muirden N, Pisasale M, et al: Breakthrough pain characteristics and syndromes in patients with cancer pain. An international survey. Palliat Med 18: $177-183,2004$.

35. Gustorff B, Dorner T, Likar R, Grisold W, Lawrence K, Schwarz F and Rieder A: Prevalence of self-reported neuropathic pain and impact on quality of life: A prospective representative survey. Acta Anaesthesiol Scand 52: 132-136, 2008.

36. Piano V, Verhagen S, Schalkwijk A, Burgers J, Kress H, Treede RD, Hekster Y, Lanteri-Minet M, Engels Y and Vissers K: Diagnosing neuropathic pain in patients with cancer: Comparative analysis of recommendations in national guidelines from European countries. Pain Pract 13: 433-439, 2013.

37. Pergolizzi JV Jr, Raffa RB, Zampogna G, Breve F, Colucci R, Schmidt WK and LeQuang JA: Comments and suggestions from pain specialists regarding the CDC's proposed opioid guidelines. Pain Pract 16: 794-808, 2016.

38. Dueñas M, Salazar A, Sanchez M, De Sola H, Ojeda B and Failde I: Relationship between using clinical practice guidelines for pain treatment and physicians' training and attitudes toward patients and the effects on patient care. Pain Pract 18: 38-47, 2018.

39. Skorpen F, Laugsand EA, Klepstad P and Kaasa S: Variable response to opioid treatment: Any genetic predictors within sight? Palliat Med 22: 310-327, 2008.

40. Sakai K, Matsuoka H, Ohtake Y, Makimura C, Izumi H, Fujita Y, Otsuka M, Tsurutani J, Nishio K, Nakagawa K and Koyama A: Incidence of carnitine deficiency in patients with cancer pain: A pilot study. Mol Clin Oncol 6: 331-333, 2017.

41. Scarborough BM and Smith CB: Optimal pain management for patients with cancer in the modern era. CA Cancer J Clin 68: 182-196, 2018.

42. Azevedo LF, Costa PA, Dias C, Agualusa L, Lemos L, Romão J, Patto T, Vaz-Serra S, Abrunhosa R, Carvalho CJ, et al: Tradução, adaptação cultural e estudo multicêntrico de validação de instrumentos para rastreio e avaliação do impacto da dor crónica. Dor 15: 6-56, 2007.

43. Cleeland CS and Ryan KM: Pain assessment: Global use of the brief pain inventory. Ann Acad Med Singapore 23: 129-138, 1994.

44. Cleeland CS, O'Mara A, Zagari M and Baas C: Integrating pain metrics into oncology clinical trials. Clin Cancer Res 17: 6646-6650, 2011.

45. Basch E, Dueck AC, Rogak LJ, Minasian LM, Kelly WK, O'Mara AM, Denicoff AM, Seisler D, Atherton PJ, Paskett E, et al: Feasibility assessment of patient reporting of symptomatic adverse events in multicenter cancer clinical trials. JAMA Oncol 3: 1043-1050, 2017.

46. Oken MM, Creech RH, Tormey DC, Horton J, Davis TE, McFadden ET and Carbone PP: Toxicity and response criteria of the Eastern Cooperative Oncology Group. Am J Clin Oncol 5: 649-655, 1982

47. Jadad AR and Browman GP: The WHO analgesic ladder for cancer pain management. Stepping up the quality of its evaluation. JAMA 274: 1870-1873, 1995.

48. Pergolizzi J, Böger RH, Budd K, Dahan A, Erdine S, Hans G, Kress HG, Langford R, Likar R, Raffa RB and Sacerdote P: Opioids and the management of chronic severe pain in the elderly: Consensus statement of an international expert panel with focus on the six clinically most often used World Health Organization Step III opioids (buprenorphine, fentanyl, hydromorphone, methadone, morphine, oxycodone). Pain Pract 8: 287-313, 2008.

49. Canser E, Martinez-Serrano B, Sancho A, Alonso-Babarro A, Vilches Y, Alonso-Yanci E, Gredilla E and Gilsanz F: Invasive techniques for pain management in palliative care: A single center experience. Pain Pract 14: 632-639, 2014.

50. van Kleef M, Mekhail N and van Zundert J: Evidence-based guidelines for interventional pain medicine according to clinical diagnoses. Pain Pract 9: 247-251, 2009.

51. Likar R, Krainer B and Sittl R: Challenging the equipotency calculation for transdermal buprenorphine: Four case studies. Int J Clin Pract 62: 152-156, 2008.

52. Cleeland CS: The measurement of pain from metastatic bone disease: Capturing the patient's experience. Clin Cancer Res 12: 6236s-6242s, 2006
53. Serlin RC, Mendoza TR, Nakamura Y, Edwards KR and Cleeland CS: When is cancer pain mild, moderate or severe? Grading pain severity by its interference with function. Pain 61: 277-284, 1995.

54. P F: Criação da Versão Portuguesa do MOS SF-36, Parte II-Testes de validação. Acta Med Port 13: 119-127, 2000.

55. Dénommé F, Kroemer $M$, Montcuquet $P$, Nallet G, Thiery-Vuillemin A, Bazan F, Mouillet G, Villanueva C, Demarchi M, Stein U, et al: Prevalence and management of pain in patients with metastatic cancer in Franche-Comté. Bull Cancer 103: 849-860, 2016 (In French).

56. van den Beuken-van Everdingen MH, de Rijke JM, Kessels AG, Schouten HC, van Kleef $M$ and Patijn J: Prevalence of pain in patients with cancer: A systematic review of the past 40 years. Ann Oncol 18: 1437-1449, 2007.

57. Castro C, Antunes L, Lunet $\mathrm{N}$ and Bento MJ: Cancer incidence predictions in the North of Portugal: Keeping population-based cancer registration up to date. Eur J Cancer Prev 25: 472-480, 2016.

58. Trama A, Foschi R, Larrañaga N, Sant M, Fuentes-Raspall R, Serraino D, Tavilla A, Van Eycken L and Nicolai N; EUROCARE-5 Working Group: Survival of male genital cancers (prostate, testis and penis) in Europe 1999-2007: Results from the EUROCARE-5 study. Eur J Cancer 51: 2206-2216, 2015.

59. Pina F, Castro C, Ferro A, Bento MJ and Lunet N: Prostate cancer incidence and mortality in Portugal: Trends, projections and regional differences. Eur J Cancer Prev 26: 404-410, 2017.

60. Sant M, Chirlaque Lopez MD, Agresti R, Sánchez Pérez MJ, Holleczek B, Bielska-Lasota M, Dimitrova N, Innos K, Katalinic A, Langseth $\mathrm{H}$, et al: Survival of women with cancers of breast and genital organs in Europe 1999-2007: Results of the EUROCARE-5 study. Eur J Cancer 51: 2191-2205, 2015.

61. Paice JA, Portenoy R, Lacchetti C, Campbell T, Cheville A, Citron M, Constine LS, Cooper A, Glare P, Keefe F, et al: Management of chronic pain in survivors of adult cancers: American society of clinical oncology clinical practice guideline. J Clin Oncol 34: 3325-3345, 2016.

62. Huber MB, Felix J, Vogelmann M and Leidl R: Health-related quality of life of the general german population in 2015: Results from the EQ-5D-5L. Int J Environ Res Public Health 14: pii: E426, 2017.

63. Santoro GC, Carrion J, Patel K, Vilchez C, Veith J, Brodie JD and Dewey SL: Sex differences in regional brain glucose metabolism following opioid withdrawal and replacement. Neuropsychopharmacology 42: 1841-1849, 2017.

64. Lami MJ, Martinez MP, Sánchez AI, Miró E, Diener FN, Prados G and Guzmán MA: Gender differences in patients with fibromyalgia undergoing cognitive-behavioral therapy for insomnia: Preliminary data. Pain Pract 16: E23-E34, 2016.

65. Suzuki N, Mashu S, Toyoda M and Nishibori M: Oral burning sensation: Prevalence and gender differences in a Japanese population. Pain Pract 10: 306-311, 2010.

66. Kong P, Yan J, Liu D, Ji Y, Wang Y, Zhuang J, Wang J, Hu X and Yue X: Skeletal-related events and overall survival of patients with bone metastasis from nonsmall cell lung cancer-A retrospective analysis. Medicine (Baltimore) 96: e9327, 2017.

67. Dworkin RH, Turk DC, Wyrwich KW, Beaton D, Cleeland CS, Farrar JT, Haythornthwaite JA, Jensen MP, Kerns RD, Ader DN, et al: Interpreting the clinical importance of treatment outcomes in chronic pain clinical trials: IMMPACT recommendations. J Pain 9: 105-121, 2008.

68. Zylla D, Kuskowski MA, Gupta K and Gupta P: Association of opioid requirement and cancer pain with survival in advanced non-small cell lung cancer. Br J Anaesth 113 (Suppl 1): i109-i116, 2014.

69. Zylla D, Steele G and Gupta P: A systematic review of the impact of pain on overall survival in patients with cancer. Support Care Cancer 25: 1687-1698, 2017.

This work is licensed under a Creative Commons Attribution-NonCommercial-NoDerivatives 4.0 International (CC BY-NC-ND 4.0) License. 